\title{
FEASIBILITY ANALYSIS OF SETTING UP CHARACTERISTIC GYMNASIUM IN COLLEGES AND UNIVERSITIES
}

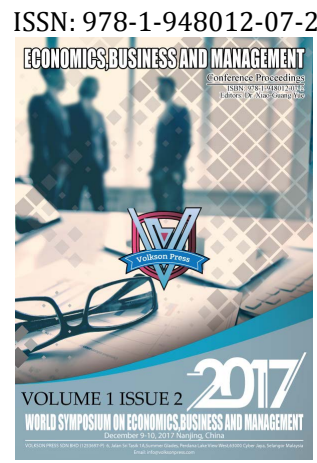

\author{
Feng Naiwen, Zhang Ludan, Zhou Yameng \\ North China Electric Power University, Beinong Street, Beijing,China \\ *Corresponding Author Email: 18601193159@163.com
}

This is an open access article distributed under the Creative Commons Attribution License, which permits unrestricted use, distribution, and reproduction in any medium, provided the original work is properly cited.

\section{ARTICLE DETAILS}

\section{ARTICLE HISTORY}

Received 27th December 2017

Accepted 29th December 2017

Available online 29th December 2017

\section{KEYWORDS:}

characteristic, gym, University, feasibility

\begin{abstract}
In response to the state of contemporary college students to enhance physical fitness, exercise more, and with the rapid development of national economy and social, contemporary youth emphasis on health and health awareness of strengthening, fitness has become a contemporary college student the essential way of life. Based on the analysis and research of the existing problems in the gymnasium in Colleges and universities, this paper puts forward the idea of setting up the characteristic gymnasium in Colleges and universities, and demonstrates and analyzes the feasibility of the project.
\end{abstract}

PROJECT BACKGROUND

With the development of social productive forces and the continuous improvement of people's living standard, the demand for body building is increasing day by day under the influence of the national vigorously promoting the development of national sports. Through to the contemporary college students fitness requirements, exercise habits and consumption level of research and survey found in many colleges and universities, college students demand for the gym and fitness affiliated facilities; Although most colleges and universities have set up the school gym at present stage, but the majority of students in the school inside the gym business model: such as operating time, fitness equipment, supplies, the personal customized service said there are still many aspects, such as great improvement and room to improve. Therefore, it is necessary to set up a characteristic gymnasium which caters to college students' fitness needs and college students' fitness habits in the campus [1].

With the progress and development of the society, the demand of the contemporary college students fitness is increasing, in this article, through the survey found that college students' demand for fitness is as high as $85.9 \%$, but the school inside the gym has certain drawbacks, after data analysis and sum-up, this article from the aspects of operating time, equipment supply, hiring and managing staff, and personalized custom four aspects to discuss the disadvantages of existing gym in colleges and universities and colleges and universities to open characteristic feasibility analysis of the gym [2].
Table 1: Statistics on fitness needs of college students

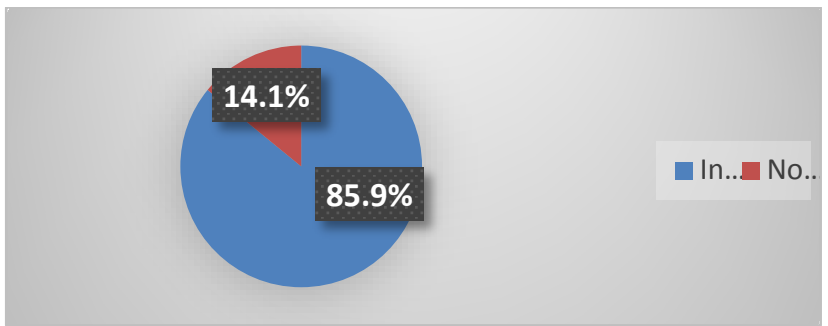

\section{FOUR ASPECTS}

\section{$2.1 \quad$ Business hours}

Due to the regularity of the time arrangement of school curriculum and the preference of some college students to the fitness period, according to the survey data, the majority of college students ' fitness time is concentrated in the evening, some college students choose the morning, followed by noon, so that the gymnasium in different business hours of supply and demand imbalance, mismatch and asymmetry phenomenon. This paper holds the point of pain, and proposes to set up a "time-price" pricing model, and realizes the gym profit model is unified with the college students ' fitness period by applying "flexible price mechanism".Based on the concentration of the college students ' fitness preference and the scarcity of the morning and noon, this paper advocates the establishment of the characteristic gymnasium should use "time-price" pricing model, in the course of operation through the lower price to guide the fitness preference of the scarce period, this kind of time sales "flexible price mechanism" Can realize the gymnasium expands the market demand and the university student fitness time multiplex unification. 
Table 2: A statistical chart of college students ' choice of fitness period

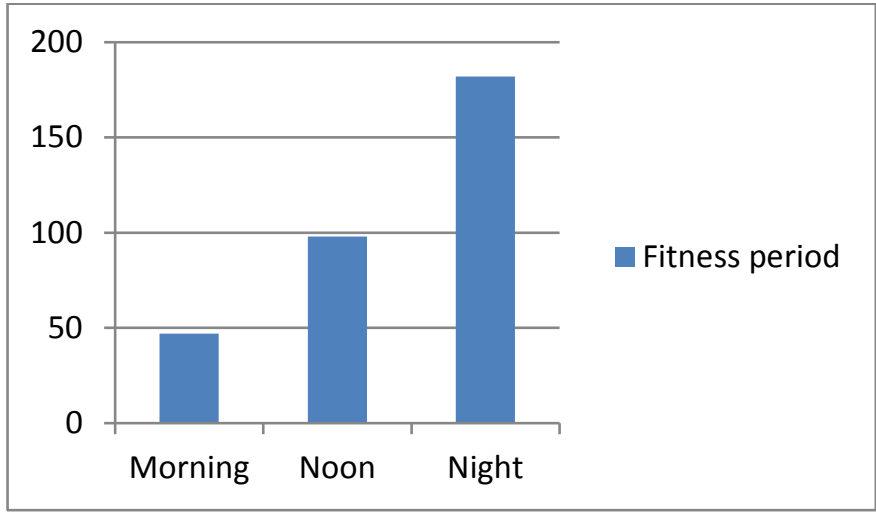

2.2

Equipment supply

According to the investigation found that the internal traditional gym, hand equipment are used for a long time, the phenomenon of old equipment and the late repair and maintenance costs already exist; on the other hand, due to the general fitness for college students tend to be more traditional aerobic mode, so there are fitness aerobic exercise on a treadmill, greater demand for equipment spinning, but disadvantages of gym offers less related equipment. Therefore, in view of the traditional fitness equipment supply quality, quantity and kind of problem, put forward the establishment of characteristic gym related measures. First of all, should be appropriate to expand the number of aerobic fitness equipment, to meet the demand, improve customer satisfaction; secondly, the business process through physical detection, artificial supervision and other means to strengthen the management of gym fitness equipment; finally, the gym can also be appropriate to seek foreign suppliers to provide low-cost, new equipment, new technology implement equipment supply.

Table 3: Statistics of College Students' preferences for fitness equipment

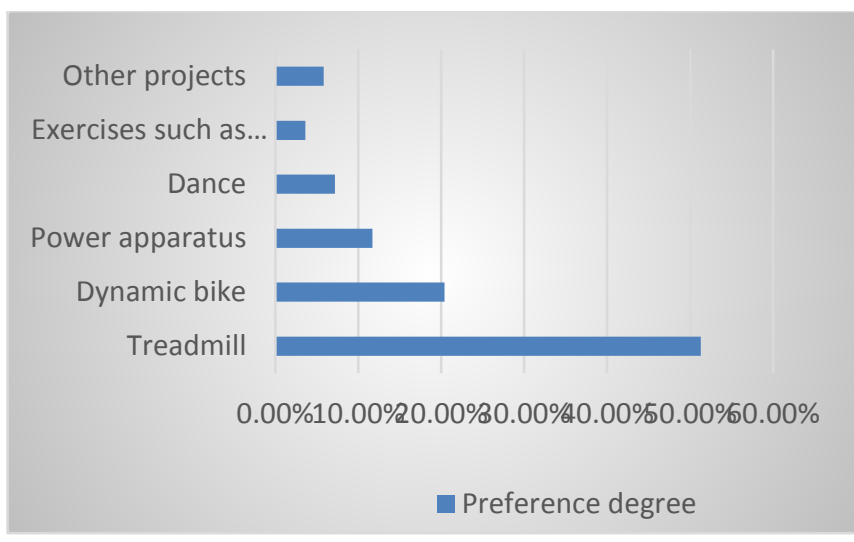

2.3

Employee recruitment and management

In view of the characteristics of the opening place in college, we can make use of the high quality human resources, such as the students in school sports and the fitness man in school, to realize the demand for fitness trainer in the gym. It also provides part-time opportunities for these sports students to play their own special skills. In terms of administrative personnel, we also recruit students with part-time will, so as to save labor costs and ensure the quality and professionalism of employees, and the combination of practicality and professionalism. In terms of staff management, we also take full account of the life habits and work schedules of university students in this special group, and adopt flexible working system for employees. Specifically, according to the law of flow in the gym every day different time period to specific arrangement, the number of employees in general, seven to nine in the evening is the largest passenger volume every day time, then the corresponding we would at this time to arrange more people think that the customer to provide a better service.

\section{$2.4 \quad$ Personalized customization}

At present, although the college students have gradually promoted the consciousness of fitness, but the existing gyms in colleges and universities do not provide fitness members with suitable coaches and related fitness programs, resulting in a lot of college students blind fitness or halfway. The traditional gymnasium management model will not only waste college students ' private time, but also may cause damage to college students ' health. So this article advocates the characteristic gymnasium should carry out personalized custom "three +" service--combine "body-building Knowledge +", "Fitness healthy slimming. "Fitness knowledge +" that is, the personal trainer can be a fitness Way +" and "fitness dining +", Carry on personalized custom course, efficient and body, such as a number of parameters such as the use of scientific instruments such as comprehensive analysis, in view of its knowledge of science related fitness and put forward private recommendations, private coaches can also personalized customized courses for customers; "Fitness mode +" The introduction of traditional aerobic and anaerobic combination classes and the introduction of health and physique management courses, enrich fitness style, improve fitness fun; "Fitness food +" is designed to provide low-fat, High-protein ingredients, fitness can not only DIY hand-made and can purchase a complete set of fitness catering, fitness to control the diet, to achieve the effect of slimming.

\section{CONCLUSION}

To sum up, the author thinks that it is feasible to set up characteristic gymnasium in Colleges and universities. We adopted the questionnaire data collection and processing of Business Hours, equipment supply, staff recruitment and management, personalized custom of these four aspects of the analysis, we can understand that there are many college students are dissatisfied with the existing inside the school gym, gym with characteristic put to us is a great demand. Through on-the-spot investigation and questionnaires we learned inside the University Gym there are existing living arrangements for special Business Hours and college students are not matching, asymmetry phenomenon, equipment supply and fitness demand and preference of contemporary college students have more serious imbalance. The existing gym for employment and management of employees is also ignored in school sports students a good human resources, the management of employees is too rigid, without considering their unique time arrangement and the law of life and the reasonable arrangement of different number of employees in different time. Personalized custom existing gym is lacking, which is why many customers give up halfway, we uphold the characteristics of the gym is responsible for every fitness attitude, for each customer the different physical conditions and personal fitness goals tailored to each person's exclusive fitness program, including specific collocation training programs and lose weight the meal.

\section{SUGGESTION}

hrough the above analysis, the author thinks that the development prospect of the specialty gymnasium in colleges and universities is good. Need to do is doing fine to do the above mentioned aspects, the advantage of our characteristic gym truly putting into effect, as well as to consider for the customer, the customer's demand as their demand, the customer's advice as a gym development momentum, continue to find their own problems and deficiencies in practice, constantly expand their characteristic advantage, the internal characteristic of colleges and universities gym fitness to be popular with the masses of teachers and students, for teachers and students to provide the most suitable for their gym and continuous efforts on the road.

\section{REFERENCE}

[1] Peng, L. 2017. Discussion on the planning and design of urban sports venues under the environment of "urban fitness circle [M]. Curriculum education research in the twenty-third phase.

[2] Haotian, J. 2017. The constitution of college students in China is declining [M]. Guangming Daily. 